\title{
PROGRAMA DE LIVROS DIDÁTICOS E MATERIAIS DE INSTRUÇÃO OPAS/OMS
}

O Programa de Livros Didáticos e Materiais de Instrução da Organjzação Pan-Americana da Saúde da Organização Mundial de Saúde (OPAS/OMS) tem o propósito de contribuir para a formação de recursos humanos na área de saúde, promovendo o hábito de leitura entre os estudantes.

A oportunidade para a aquisição de livros-texto a preços reduzidos em relação ao mercado facilita a formação de uma biblioteca de enfer. magem, assim como o instrumental básico para o aperfeiçoamento técnico-científico do estudante.

De acordo com os termos de um Convênio assinado entre a OPAS/ /OMS e os Ministérios da Saúde e da Educação e Cultura, o Programa funciona em diversas Universidades. A Escola de Enfermagem da USP desde 1975 está vinculada ao Programa atendendo aos pedidos dos estudantes.

A partir de 1980 foram incluídos no Programa e postos à disposição de estudantes estetoscópios e aparelhos de pressão.

No momento existem 27 títulos de livros-texto básicos e de enfermagem colocados à venda, e é de interesse do Programa que outros livros editados no Brasil sejam nele incluidos, para melhor embasamento teórico dos profissionais de enfermagem.

Diretora da Escola de Enfermagem da USP. Professora Titular do Departamento de Enfermagem Médico-Cirúrgico da Escola de Enfermagem da USP - disciplina Nutriçáo o Dietética aplicadas a Finfermagem. 